ISSN electrónico: 2172-9077

DOI: https://doi.org/10.14201/fjc202123301304

\title{
UN MANUAL DE EMERGENCIA PARA NUESTRO CINE RECIENTE
}

\section{An emergency manual for our recent cinema}

\section{Laura PACHECO-JIMÉNEZ}

Estudiante de doctorado en la Universidad de Sevilla, España.

E-mail: laurapachecojimenez@gmail.com

(iD https://orcid.org/0000-0002-6610-6567

Fecha de recepción de la reseña: 09/03/2021

Fecha de aceptación definitiva: 5/10/2021

José Luis Sánchez Noriega (ed.) CIRE ESPAROL BI LA ERA DIGITAL: EMEROSBCIAS Y ERCRUCIJADAS

एपIERTE

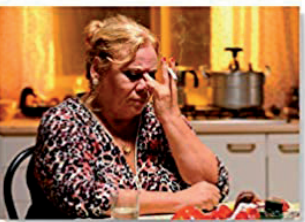

SÁNCHEZ-NORIEGA, José Luis. Cine español en la era digital: emergencias y encrucijadas. Editorial Laertes, $n^{\circ}$ 59. Barcelona, 2020, 493 pp.

\section{Introducción}

La historia del cine español ha sido estudiada, desglosada y divulgada por multitud de investigadores que han aportado una profusa cantidad de materiales de excelente calidad para todos los interesados en el tema, tanto de dentro del mundo académico como de fuera. Desde los manuales de Gubern, Monterde, Perucha, Rimbau y Torreiro (1995) o Caparrós Lera (2007), que hacen un recorrido cronológico por los acontecimientos en los que se origina y desarrolla el cine en España hasta la actualidad, hasta Castro García (2009) que analiza los filmes de la Transición con perspectiva de género, pasando por otro tipo de materiales que se centran en épocas concretas como 'Los años del NO-DO' (Xavier Gassió, 2012), que en forma de documental seriado analiza los años políticamente más convulsos del cine español, entre muchos otros. 
De entre los investigadores e historiadores que analizan el cine en España cabe destacar la colección que editan y coordinan Huerta, Pérez Morán y Sánchez Noriega, en los que un amplio grupo de especialistas analizan el cine del tardofranquismo (2012 y 2013), la Transición (2014) y los últimos decenios del siglo XX (2017) y cuya última obra para la editorial Laertes se centra en el cine en la era digital, es decir, en el periodo de 1996 a 2011. Todos ellos, junto con otros tantos monográficos de este grupo de investigadores, en palabras de Sánchez Noriega, sirven al lector "como materiales para una Historia del Cine Español» (p. 7).

'Cine español en la era digital: emergencias y encrucijadas' se configura como una cartografía de la sociedad española y de los movimientos políticos y sociales que afectaron al cine en el periodo analizado, tales como cambios de gobierno, el fin de la banda terrorista ETA o el atentado del 15-M. Este contexto sumado a la digitalización del cine, con el consecuente abaratamiento de los costes de producción, provoca, por un lado, un aumento en la producción de las cintas y, por otro, una mayor implicación social de las mismas debido al contexto sociocultural en el que se desarrollan, lo que hace que el panorama del cine español de estos años sea harto interesante.

Tras una breve introducción que corre a cargo del propio Sánchez Noriega, se da paso a un capítulo firmado por Pereira Castañares, donde se tratan los aspectos más relevantes de la política internacional y sus consecuencias en la sociedad en los gobiernos de Aznar y Zapatero, así como la relevancia de este agitado escenario para el cine, con mención especial al cine de autor que en los últimos tiempos ha abandonado, en parte, las salas de exhibición para mostrarse en otros espacios como los museos, lo que provoca que la experiencia de recepción por parte del espectador haya cambiado radicalmente.

En el capítulo ulterior, Pérez Morán y Sánchez Noriega desgranan los géneros y formatos que destacan en el periodo con pequeños subapartados que tratan desde las historias mínimas hasta el compromiso de tratar la corrupción política, a veces incluso de forma premonitoria como en el extraordinario caso de 'La caja 507' (Enrique Urbizu, 2002), que trata el tema de la corrupción urbanística en la Costa del Sol antes de que se destape el Caso Malay. Además, ponen el foco de atención en el tratamiento de la memoria histórica, representación de minorías o adaptaciones literarias en un periodo en el que estas temáticas coexisten con los cambios en los hábitos de consumo de los espectadores tras la irrupción del streaming.

Virginia Guarinos, en su apartado, realiza un repaso por el panorama de directoras de cine español que han proliferado en estos años, siguiendo la estela de libros que abarcan desde los albores del cine como Directoras de cine español. Ayer, boy y mañana, mostrando talentos (Núñez Domínguez, Silva Ortega y Vera Balanza, 2012) o Desenfocadas. Cineastas españolas y discursos de género (Zecchi, 2014). Guarinos ahonda en los temas que tratan en sus cintas, así como en las diferentes perspectivas que aportan, con mención especial a cómo trabajan directoras en un cine tan masculinizado como el pornográfico. Es interesante la comparación con un trabajo anterior de Zurián (2017), que concluye que las mujeres en el sector cinematográfico proliferan con el abaratamiento de las tecnologías, pero que la igualdad aún queda lejos debido al alto porcentaje de directoras con trayectorias incipientes que no llegan a estrenar su segunda película. Si bien Guarinos no lo contradice, tan solo cuatro años después, el panorama es diferente y concluye que hay realizadoras que están asentando sus 
carreras -aunque no al ritmo de los varones-, lo que propicia que ser directora de cine en España ya no sea una empresa tan solitaria.

No queda sin estudio el propio espectador del cine español, y Fernando Ramos Arenas analiza su comportamiento en esos años en los que la asistencia a las salas se ve muy afectada por la piratería, en primer lugar, y por el control gubernamental de la misma, a posteriori.

Estos apartados vienen seguidos de un esquemático desglose cronológico de los acontecimientos sociopolíticos más importantes de cada año acompañados de breves análisis de las cintas más relevantes estrenadas en ese contexto encabezados por una ficha técnica completa que incluye producción, guión, dirección, fotografía, música, montaje, dirección artística e intérpretes. El lector podrá (re) conocer un total de 131 filmes, estudiados por casi una veintena de autores al lado de cronogramas que resaltan los acontecimientos político-sociales más relevantes de cada año, para que se entienda la cinta, pero también su contexto. Así, se compone un verdadero mapa de cómo es el cine español de la era digital y qué películas suponen la diferencia en un espacio-tiempo marcado por las transformaciones temáticas, pero también de géneros y formatos, donde los directores abogan por el compromiso social, pero también por el cuidado de la técnica y la estética.

En definitiva, la descripción del manual que hace su propio editor como «materiales para una Historia del Cine Español» es sucinta, pero a la vez precisa, pues es una obra verdaderamente útil para conocer los filmes del periodo digital y el contexto en el que se producen, para que el lector comprenda los elementos sociológicos y políticos que han acompañado a nuestro cine más reciente y para poder ahondar en la producción cinematográfica de unos años que, precisamente por su escasa distancia temporal, no están lo suficientemente tratados en manuales para su análisis.

\section{Bibliografía}

Bovaira, F. (productor) y Urbizu, E. (director) (2001). La caja 507 [cinta cinematográfica]. España: Sogecine.

Caparrós Lera, J.M. (2007). Historia del cine español. Madrid, España: T \& B Editores.

Castro García, A. La representación de la mujer en el cine español de la Transición (1973-1982). Oviedo, España: KRK Ediciones.

Gassió, X. (2012). Los años del NO-DO [serie documental]. España: TVE.

Gubern, R., Monterde, J.E., Pérez Perucha, J., Riambau, E. y Torreiro, C. (1995). Historia del cine español. Madrid, España: Ediciones Cátedra.

Huerta, M.A. y Pérez Morán, E. (eds.) (2012). El cine popular del tardofranquismo. Análisis Fílmico, Salamanca, España: Los Barruecos

Huerta, M.A. y Pérez Morán, E. (eds.) (2013). El «cine de barrio» tardofranquista. Reflejo de una sociedad, Madrid, España: Biblioteca Nueva.

Núñez Domínguez, T., Silva Ortega, M. \& Vera Balanza, T. (coords.) (2012). Directoras de cine español. Ayer, hoy y mañana, mostrando talentos. Sevilla: Fundación Audiovisual de Andalucía.

Sánchez Noriega, J.L. (ed.) (2014). Filmando el cambio social. Las películas de la Transición. Barcelona, España: Laertes.

Sánchez Noriega, J.L. (ed.) (2017). Trayectorias, ciclos y miradas del cine español (1982-1998). Barcelona, España: Laertes. 
Zecchi, B. (2014). Desenfocadas. Cineastas españolas y discursos de género. Barcelona: Centre Dona i Literatura.

Zurian, F. A. (ed.) (2017). Miradas de mujer. Cineastas españolas para el siglo XXI. Madrid: Editorial Fundamentos. 